\title{
Women's Expectations of Health Care Providers' Communication and Behavior in the Delivery Room: a Cross-sectional Study in the Kurdistan Region of Iraq
}

Hamdia Mirkhan Ahmed ( $\boldsymbol{\sim}$ hamdia.ahmed@hmu.edu.krd)

Center for Research and Education in Women's Health Hawler Medical University

\section{Research article}

Keywords: expectation, women, childbirth, behavior, communication, health care provider

Posted Date: January 5th, 2021

DOI: https://doi.org/10.21203/rs.3.rs-137295/v1

License: (c) (7) This work is licensed under a Creative Commons Attribution 4.0 International License. Read Full License 


\section{Abstract}

Background: Having a positive childbirth experience is highlighted as being important by the World Health Organization (WHO). One way of achieving this goal is to fulfill the expectations of women. This study aimed to find out women's expectations in the delivery room and to determine the association between their overall level of expectation and sociodemographic and obstetrical characteristics.

Methods: A cross-sectional study was conducted with 1196 women who agreed to participate and who met the inclusion criteria through convenient sampling. Data were collected through direct interviews after receiving informed consent. Sociodemographic and obstetric data, along with expectations items, were summarized by frequency and percentage. A chi-square test was used to find the association between overall expectation and sociodemographic and obstetric variables, general satisfaction with birth care, and communication of health care providers.

Results: A majority of the study sample expected the following from health care providers in the delivery room: presence (78.6\%), positive and calming verbal (76.3\%) and nonverbal expressions (72.3\%), environmental control (74.6\%), encouragement of different positions and mobilization (75.9\%), hygiene (77.5\%), promotion of urinary elimination (75.8\%), and instruction on breathing and relaxation (71.9\%). The overall expectation level was divided into "high expectations" (68.6), "slight expectation" (29.9), and "no expectation" (1.4).

Conclusion: Knowing the women's expectations in the delivery room and how to effectuate them helps to inform plans of care and may also increase women's satisfaction level, providing them with a more positive birth experience.

\section{Background}

Each year, approximately 140 million births occur globally (1). Among a majority of women with no identified risk factors for complication at the onset of labor, these births are vaginal $(2,3)$.

Consumer evaluations of health care are now an established component of quality assessment, mainly through surveys of patient satisfaction and experience and patient-based health outcome studies. It is generally acknowledged that planners need to understand the expectations underlying patients' views in order to interpret their feedback (4). Understanding experience-of-care is a critical aspect of ensuring high-quality labor and childbirth care and improved woman-centered outcomes, and is not just complementary to the provision of routine clinical practices (5). Women experience a wide range of pain in labor and have an equally wide-range of responses to it. Women's reactions to labor pain may be influenced by the circumstances of her labor, including the environment that it takes place in and the support-level that she receives (6).

A positive childbirth experience is a significant endpoint for all women undergoing labor. A positive childbirth experience is defined as one that fulfills or exceeds a woman's prior personal and socio-cultural beliefs and expectations, including giving birth to a healthy baby in a clinically and psychologically safe environment with continuity of practical and emotional support from a birth companion(s) and kind, technically competent clinical staff (4). As highlighted in the World Health Organization (WHO) framework for improving the quality of care for pregnant women during childbirth, the experience of care is as important as clinical care providers in achieving the desired person-centered outcomes (7).

Further, awareness of patients' expectations for their care and understanding the formation of these expectations are potentially important aspects for policy development and service provision. For example, if health-care providers are aware of their patients' expectations for care, then they can plan to address these expectations in a timely way in order to better meet the patients' needs and, in turn, to increase patient satisfaction (4). Exploring women's expectations regarding communication and behaviors of health care providers during labor may help to create an environment that leads to a positive experience and increases satisfaction with care by midwives and physicians. Therefore, this study, which is a part of a larger research project, aimed to find out women's expectations in the delivery room under the following three domains: a) emotional support, b) physical support and comfort measures, c) providing information, advice, and advocacy. Another goal of this study was to find the association between overall level of expectation with the women's sociodemographic and obstetrical characteristics, general satisfaction with birth care, and overall satisfaction with communication of health care providers in the delivery room.

\section{Methods \\ Study design and sample}

A cross-sectional study was conducted from January 20, 2019, to March 15, 2019 in Erbil city, located in the Kurdistan region of Iraq. Through convenient sampling, 1234 women who met the inclusion criteria were recruited from a total of 1500 women, and 1196 women agreed to participate. The inclusion criteria included having at least one vaginal-birth experience within the past year, either in Rezgary Hospital, a Maternity Teaching Hospital, or Malafandy, a primary health center in Erbil city. The recruited women were either accompanying another person to the hospital or health center, or were coming to immunize one of their children. Maternity Teaching Hospital is the biggest specialized public hospital for women's health care, especially for labor and delivery care as the hospital has 300 hundred beds and 30 delivery room beds. Rezgary Hospital is a general hospital that includes a unit for women's health care services with a capacity of 6 beds. Malafandy Primary Health Center has a small unit for women with low-risk and normal health conditions, and has a capacity of only 5 beds for labor and delivery care. All of these institutions are public health settings. Women who delivered in a private hospital or who had a psychological disorder were excluded. 
Data were collected through direct interviews after receiving informed consent. The purpose of the study was explained to the women and they were assured that their personal information would remain confidential. Three midwifery students helped the researcher with data collection after they were trained to interview women and collect the data. A questionnaire was developed by the author after a review of the literature and included two main parts. The first part consisted of sociodemographic and obstetrical characteristics such as age, educational level, occupation, residency, parity, history of abortion, sex of the baby, admission of the baby to the intensive care unit (ICU) and a list of expectations (20 items) regarding communications. The second part consisted of questions about the behavior of health care providers categorized under the following dimensions: emotional support, physical support and comfort measures, and providing information, advice, and advocacy. Two questions were asked regarding general satisfaction with birth care and general satisfaction with communications of health care providers.

\section{Variables}

Responses to expectation items were categorized as "mentioned" (score = 2) or "not mentioned" (score $=1$ ). Overall expectation for each dimension was categorized as "highly expected" (total score =34-40), "slightly expected" (total score = 27-33), or "not expected" (total score = 20-26).

Exposure variables were age, education level, occupation, residency, parity, history of episiotomy, and general satisfaction with birth care and communication of health care providers. History of episiotomy described the mother's most recent delivery. Age was grouped as less than 20 years old (considered an adolescent), 20 to 29,30 to 39, and 40 or more years old. For educational level, "basic" was defined as finishing 9 years of education, "secondary" was defined as completing 12 years of education, and "institute and BSc" included those who finished 2 or more years at a university. Residency was divided as "urban" (which included Erbil city), "suburban" (which included towns within a half-hour to one hour drive from Erbil city), and "rural" (which included towns and villages beyond the suburban areas). As most Kurdish women are housewives, occupation was grouped as "housewife," "employed," or "student." Parity was grouped as "primipara" (1 delivery), "multipara" (2 to 4 deliveries), and "grand multipara" (5 or more deliveries).

\section{Statistical analysis}

Data was entered into and analyzed using the SPSS program (V.21) and included frequency, percentage, and chi-square test. Sociodemographic and obstetric data and expectation items were summarized by frequency and percentage. A chi-square test was used to find the association between overall expectation and sociodemographic and obstetric variables, general satisfaction with birth care, and communication of health care providers.

The study was approved by the Scientific Committee of the College of Nursing/Hawler Medical University.

\section{Results}

Sociodemographic characteristics of the study sample are shown in Table 1 . The highest percentage (49.9\%) of the study sample were aged between $20-$ 29 years old. The highest percentage (40.8\%) of the sample graduated from basic school and more than half (54.4\%) of residents were from an urban area. A majority (92.8\%) of participants were housewives. The highest percentage $(62.5 \%)$ of the women were multigravida and $34.2 \%$ had a history of abortion. Of the participants, $91.2 \%$ had no history of a deceased baby and $63.6 \%$ had experienced episiotomy or laceration during delivery. Only $13.1 \%$ of their babies had been admitted to a hospital (Table 1).

The majority of the study sample expected the following from their health care providers in the delivery room: presence (78.6\%), positive and calming verbal expressions (76.3\%), positive nonverbal expressions (72.3\%), environmental control (74.6\%), encouragement of different positions and mobilization (75.9\%), hygiene (77.5\%), promotion of urinary elimination (75.8\%), and instruction on breathing and relaxation (71.9\%). The percentage of other expectations is shown in Table 2. 
Table 1

Sociodemographic and obstetric characteristics of the study sample

\begin{tabular}{|c|c|c|}
\hline Variables & No. & $\%$ \\
\hline \multicolumn{3}{|l|}{ Age } \\
\hline - less than 20 & 93 & 7.8 \\
\hline$-20-29$ & 597 & 49.9 \\
\hline$-30-39$ & 445 & 37.2 \\
\hline - 40 and more & 61 & 5.1 \\
\hline \multicolumn{3}{|l|}{ Education level } \\
\hline - Illiterate & 268 & 22.4 \\
\hline - read and write & 168 & 14.0 \\
\hline - basic & 488 & 40.8 \\
\hline - secondary & 139 & 11.6 \\
\hline - institute /BSc & 133 & 11.1 \\
\hline \multicolumn{3}{|l|}{ Residency } \\
\hline - urban & 651 & 54.4 \\
\hline - suburban & 340 & 28.4 \\
\hline - rural & 205 & 17.1 \\
\hline \multicolumn{3}{|l|}{ Occupation } \\
\hline - housewife & 1110 & 92.8 \\
\hline - employment & 59 & 4.9 \\
\hline - student & 27 & 2.3 \\
\hline \multicolumn{3}{|l|}{ Parity } \\
\hline - primipara & 238 & 19.9 \\
\hline - multipara & 748 & 62.5 \\
\hline - grand multipara & 210 & 17.6 \\
\hline \multicolumn{3}{|l|}{ Having abortion } \\
\hline - No abortion & 787 & 65.8 \\
\hline$-1-2$ & 356 & 29.8 \\
\hline - 3 and more & 53 & 4.4 \\
\hline \multicolumn{3}{|l|}{ Dead baby } \\
\hline-0 & 1091 & 91.2 \\
\hline-1 & 88 & 7.4 \\
\hline$-2-3$ & 17 & 1.4 \\
\hline \multicolumn{3}{|c|}{$\begin{array}{l}\text { Episiotomy \& laceration (in last } \\
\text { delivery) }\end{array}$} \\
\hline - Yes & 101 & 03.0 \\
\hline- no & 435 & 36.4 \\
\hline \multicolumn{3}{|l|}{ Sex of baby } \\
\hline - male & 581 & 48.6 \\
\hline - female & 600 & 50.2 \\
\hline - twin & 15 & 1.3 \\
\hline
\end{tabular}




\begin{tabular}{|lcc|}
\hline Variables & No. & $\%$ \\
\hline Admission to NICU & & \\
- yes & 157 & 13.1 \\
- no & 1039 & 86.9 \\
\hline
\end{tabular}

Table 2

Women's expectation regarding the communication and behavior of nurses, midwives, and physicians in the delivery room.

\begin{tabular}{|c|c|c|}
\hline Expectations & $\begin{array}{l}\text { Mentioned } \\
\text { No.(\%) }\end{array}$ & $\begin{array}{l}\text { Not mentioned } \\
\text { No.(\%) }\end{array}$ \\
\hline \multicolumn{3}{|l|}{ A- Emotional support } \\
\hline Presence & $940(78.6 \%)$ & 256(21.4) \\
\hline Demonstrating an effective caring attitude & $790(66.1)$ & 406(33.9) \\
\hline Positive and calming verbal expressions & $912(76.3)$ & 284(23.7) \\
\hline Nonverbal expressions & $865(72.3)$ & $331(27.7)$ \\
\hline Distraction & $614(51.3)$ & $582(48.7)$ \\
\hline Use of humor & $459(38.4)$ & $737(61.6)$ \\
\hline \multicolumn{3}{|l|}{ B- Physical support and comfort measures } \\
\hline Environmental control & $892(74.6)$ & $304(25.4)$ \\
\hline Encouragement of different positions and mobilization & $908(75.9)$ & $288(24.1)$ \\
\hline Touch, massage & $595(49.7)$ & $601(50.3)$ \\
\hline Application of hot and cold packs & $769(64.3)$ & $427(35.7)$ \\
\hline Hygiene & $927(77.5)$ & $269(22.5)$ \\
\hline Promotion of urinary elimination & $906(75.8)$ & $290(24.2)$ \\
\hline Nourishment & $653(54.6)$ & $543(45.4)$ \\
\hline \multicolumn{3}{|l|}{ C- Giving Information and advice, and advocacy } \\
\hline listening to women's views & $796(66.6)$ & $400(33.4)$ \\
\hline Instruction on breathing and relaxation & $860(71.9)$ & $336(28.1)$ \\
\hline Information about routines, Procedures and progress & $746(62.4)$ & $450(37.6)$ \\
\hline Protecting the client & $497(41.6)$ & $699(58.4)$ \\
\hline Assisting the client to make informed choices & $584(48.8)$ & $612(51.2)$ \\
\hline Being the client's voice when required & $556(46.5)$ & $640(53.5)$ \\
\hline Conflict resolution & $538(45)$ & $658(55)$ \\
\hline
\end{tabular}

Table 3 shows the overall domains of women's expectations. The majority of women expected emotional support and physical comfort measures, and nearly half expected information, advice, and advocacy during labor and delivery.

Table 3

Overall expectation domains of thestudy sample

\begin{tabular}{|llll|}
\hline Domains & $\begin{array}{l}\text { High expectation } \\
\text { No (\%) }\end{array}$ & $\begin{array}{l}\text { Slight expectation } \\
\text { No (\%) }\end{array}$ & $\begin{array}{l}\text { No expectation } \\
\text { No (\%) }\end{array}$ \\
\hline Emotional support & $823(68.8)$ & $257(21.5)$ & $116(9.7)$ \\
\hline Physical support and comfort measures & $887(74.2)$ & $265(22.2)$ & $44(3.7)$ \\
\hline Giving information and advice, and advocacy & $578(48.3)$ & $484(40.5)$ & $134(11.2)$ \\
\hline Overall expectations (all domains) & $\mathbf{8 2 1 ( 6 8 . 6 )}$ & $\mathbf{3 5 8 ( 2 9 . 9 )}$ & $\mathbf{1 7 ( 1 . 4 )}$ \\
\hline
\end{tabular}

Page 5/9 
There was a significant association between women's overall expectation and the following sociodemographic and obstetrical variables: level of education, occupation, residency, and parity. There was a highly significant association between general satisfaction with care during birth and overall satisfaction with communication of health care providers (Table 4).

Table 4

Association between overall expectations with some variables

\begin{tabular}{|c|c|c|c|c|}
\hline \multirow[t]{3}{*}{ Variables } & \multicolumn{3}{|c|}{ Level of expectation } & \multirow[t]{3}{*}{ P-value } \\
\hline & $\begin{array}{l}\text { Highly } \\
\text { expected }\end{array}$ & $\begin{array}{l}\text { Slightly } \\
\text { expected }\end{array}$ & $\begin{array}{l}\text { Not } \\
\text { expected }\end{array}$ & \\
\hline & No (\%) & No (\%) & No (\%) & \\
\hline Age group & & & & 0.591 \\
\hline - less than 20 & $59(63.4)$ & $34(36.6)$ & $0(0)$ & \\
\hline$-20-29$ & $408(68.3)$ & $181(30.3)$ & $8(1.3)$ & \\
\hline$-30-39$ & 309 (69.4) & $128(28.8)$ & $8(1.8)$ & \\
\hline - 40 and more & $45(73.8)$ & $15(24.6)$ & $1(1.6)$ & \\
\hline Level of education & & & & 0.028 \\
\hline - illiterate & $194(72.4)$ & $71(26.5)$ & $3(1.1)$ & \\
\hline - read and write & $113(67.3)$ & $52(31)$ & $3(1.8)$ & \\
\hline - basic & 344 (70.5) & $138(28.3)$ & $6(1.2)$ & \\
\hline - secondary & $92(66.2)$ & $42(30.2)$ & $5(3.6)$ & \\
\hline - institute /BSc & $58.6(78)$ & $55(41.4)$ & $0(0)$ & \\
\hline Occupation & & & & $0.053^{*}$ \\
\hline - housewife & $773(69.6)$ & 321 (28.9) & $1.6(1.4)$ & \\
\hline - employed & $35(59.3)$ & $23(39)$ & $1(1.7)$ & \\
\hline - student & $13(48.1)$ & $14(51.9)$ & $0(0)$ & \\
\hline Residency & & & & $0.003^{*}$ \\
\hline - urban & $446(68.5)$ & 199 (30.6) & $6(0.9)$ & \\
\hline - suburban & $252(74.1)$ & $81(23.8)$ & $7(2.1)$ & \\
\hline - rural area & $123(60)$ & $78(38)$ & $4(2)$ & \\
\hline Parity & & & & $0.001 *$ \\
\hline - primipara & $143(60.1)$ & 95 (39.9) & $0(0)$ & \\
\hline - multipara & $526(70.3)$ & $208(27.8)$ & $14(1.9)$ & \\
\hline - grand multi para & $152(72.4)$ & $55(26.2)$ & $3(1.4)$ & \\
\hline Generally satisfied with care during birth & & & & $<0.001^{*}$ \\
\hline - yes & 746 (79.9) & $185(19.8)$ & $3(0.3)$ & \\
\hline- no & $49(25.9)$ & $126(66.7)$ & $14(7.4)$ & \\
\hline - partially & $26(35.6)$ & $47(64.4)$ & $0(0)$ & \\
\hline Overall satisfaction with communication of & & & & $<0.001$ \\
\hline ctiof & $642(91.8)$ & $57(8.2)$ & $0(0)$ & \\
\hline - not satisfied & $179(36.0)$ & $301(60.6)$ & $17(3.4)$ & \\
\hline
\end{tabular}

\section{Discussion}

In the present study, women's expectations of their health care providers in terms of their communication and behavior in the delivery room were examined. Two-thirds of the women interviewed had high expectations. Specifically, a majority of women had high expectations for emotional and physical support, 
comfort measures, and being provided with information, advice, and advocacy by midwives and physicians. Women who had high expectations in the above-mentioned domains were generally satisfied with the care that they received during birth and with the communication of health care providers. Women who had a higher level of education, were housewives, lived in a suburban area, or were grand multipara had high expectations.

It is worth mentioning that none of the women interviewed had taken an antenatal birth class.

There are many studies with concurrent results to the present study. For example, in a phenomenological qualitative study in Turkey, researchers contentanalyzed women's expectations of nurses during vaginal birth and summarized the following three themes: 1) physiological support needs including fulfillment of personal care needs, provision of support to cope with pain, and provision of freedom of mobility; 2) psychological support needs including not being left alone, minimization of fear, receiving support from family and/or friends, provision of support from spouses, having a positive relationship with the team, and protection of privacy; 3 ) fulfillment of knowledge needs including being informed about the process of delivery and minimization of negative effects of the delivery room (8).

An analytical-cross sectional study in Egypt, which aimed to determine women's preferences and needs during labor, found twenty-two need requirements. The highest-ranked needs for parturient women during labor were maintaining privacy through all procedures, accessibility of nurses, demonstration of empathy, ability to vent and express fear and anxiety, quick response to requests, frequent monitoring, accessibility of caring medical staff, and short delivery (9). In another cross-sectional study in the same country, mothers were asked about their satisfaction with birth care services. Although most participants were satisfied by the delivery service provided to them, a small group of mothers' were dissatisfied due to lack of communication, perceived lack of privacy during the hospital stay, and obligatory blood donation (10).

In India, a qualitative descriptive analysis indicated that women prioritized the availability of doctors at the facility, availability of medicines, food, ambulance services, maintenance of cleanliness and hygiene, privacy, good and safe delivery with no complications, client-provider interaction, and financial cost of care. This study concluded that understanding women's expectations and matching them with providers' perspectives of care is critical for efforts to improve the quality of care and thereby impact maternal outcomes (11).

Another study found that obtaining permission and consent throughout the delivery care process, finding alternative ways of gaining patient cooperation that does not involve verbal or physical abuse, and consulting women on their rights and what to expect during labor and childbirth are necessary for women to have positive experiences of care and more greatly emphasizes a person-centered approach to care (12).

A population-based cross-sectional study including 4358 mothers who gave birth in southern Mozambique concluded that satisfaction with childbirth was driven by the proposed factors of communication, respect and dignity, and emotional support, as well as health systems factors (13).

A qualitative study that was carried out in Sweden concluded that first-time mother felt empowered by trustworthy relationships with professional and their partners. When women felt empowered, they also felt in control, felt the strength of their bodies, and also felt more satisfaction and reassurance, along with experiencing better pain management (14).

Ultimately, the abovementioned research, along with our present study, show that women's satisfaction with verbal and nonverbal communication of health care providers in the delivery room is associated with their satisfaction with birth care. Improving the communication skills of health care providers may be a considerable part of improving care in the delivery room (15). Further, effective communication is an essential component of the delivery of healthcare. Patients expect social niceties like greetings, social smiles, offering a seat, avoiding jargon, adequate time, paraphrasing and empathy. They require not just instructions but also explanations, and also desire opportunity to express their opinions, along with being allowed to help in the decisionmaking process (16).

Post-consultation expectation, perceived health status, and perceived control of health were factors identified as increasing patient satisfaction. In addition, the presence of any disappointments or worries, previous bad experiences with the health care system, and a perceived lack of influence on the consultation had a negative influence on satisfaction (17).

The large sample size is a strength of this study. However, this study examined women's expectations of midwives/nurses and physicians separately, which may be a weakness of the present study. This separation was decided given that in Iraq, physicians are the dominant clinical decision maker for patients.

\section{Conclusions}

This study found that presence, positive and calming verbal and nonverbal expressions, environmental control, encouragement of different positions and mobilization, hygiene, promotion of urinary elimination, and instruction on breathing and relaxation are highly expected by parturient women, followed by demonstrating an effective caring attitude, listening to women's views, application of hot and cold packs, information about routines and procedures, and progress updates. Knowing women's expectations in the delivery room and being able to effectuate them may be one of the best approaches to care planning, and it may also help to increase expecting mothers' satisfaction levels and help them to have a positive birth experience.

\section{Abbreviations}

WHO: World Health Organization 


\section{Declarations}

- Ethics approval and consent to participate: the proposal of the study approved by the Scientific Committee of College of Nursing/Hawler Medical University. Verbal informed consent was taken from all study participants. This is worth to mentioning that in our society, written consent is not common as they are more comfort with no signing any documents. This is approved by Ethical Committee of mentioned college.

- Consent for publication: not applicable.

- Availability of data and material: The datasets used and/or analyzed during the current study are available from the corresponding author upon reasonable request.

- Competing interests: The authors declare that they have no competing interests.

- Funding: Not applicable.

- Authors' contributions: HMA initiated the idea, prepared the proposal, analyzed, and interpreted the patient data regarding their quality of life, and wrote and approved the final manuscript.

- Acknowledgements: Many thanks to Ms. Mhabad Abdulla Qadir, Ms. Ahang Najmadin Muhamad, and Ms. Golnar Shex Ahmed Mostafa, the three midwifery students who helped the researcher with data collection. Thanks also to Ms. Noora Reffat, MPH, a native English speaker who helped to edit this paper as a native English speaker.

\section{References}

1. The state of the world's children: a fair chance for every child. 2016; New York (NY): United Nations Children's Fund. https://www.unicef.org/ publications/files/UNICEF_SOWC_2016.pdf

2. Danilack VA, Nunes AP, Phipps MG. Unexpected complications of low-risk pregnancies in the United States. Am J Obstet Gynecol. 2015;212(6):809.e16.

3. NICE clinical guideline 190. Intrapartum care for healthy women and babies. 2014; London: National Institute for Health and Care Excellence; http://www.geburtshaus.ch/documents/upload/ NICE_clinical_guideline_190_dec2014.pdf

4. Bowling A, Rowe G, Lambert N, Waddington M, Mahtani KR, Kenten C, Howe A, Francis SA. The measurement of patients' expectations for health care: a review and psychometric testing of a measure of patients' expectations. Health Technology Assessment. 2012; Vol. 16: No. 30

5. WHO (World Health Organization). WHO recommendations Intrapartum care for a positive childbirth, 2018; experiencehttps://apps.who.int/iris/bitstream/handle/10665/260178/9789241550215eng.pdf;jsessionid=7E800B590A164DC7FC879E73B480D6FC? sequence $=1$

6. The Royal College of Midwives. Evidence-based guidelines for midwifery-led care in labor.2012

7. Tunçalp Ö, Were WM, MacLennan C, Oladapo OT, Gülmezoglu AM, Bahl R, et al. Quality of care for pregnant women and newborns - the WHO vision. BJOG. 2015;122(8):1045-9.

8. Cicek O, Eylul D, Mete S. Women's Expectations from Delivery Nurses of Vaginal Birth: A Qualitative Study. International Journal of Caring Sciences, 2018; 11(2):831.

9. Abdel Ghani RM, Berggren V. Parturient Needs during Labor: Egyptian Women's Perspective toward Childbirth Experience, a Step toward an Excellence in Clinical Practice. J Basic Appl Sci Res.2011; 1(12)2935-2943.

10. Sayed W, Abd ElAal DE, Mohammed HS, Abbas AM, Zahran KM. Maternal satisfaction with delivery services at a tertiary university hospital in upper Egypt, is it actually satisfying? Int J Reprod Contracept Obstet Gynecol. 2018 Jul;7(7):2547-2552. DOI: http://dx.doi.org/10.18203/23201770.ijrcog20182859

11. Bhattacharyya S, Srivastava A, Saxena M, Gogoi M, Dwivedi P, Giessler K. Do women's perspectives of quality of care during childbirth match with those of providers? A qualitative study in Uttar Pradesh, India. Global Health Action. 2018;11(1). https://doi.org/10.1080/16549716.2018.1527971, Journal

12. Sudhinaraset M, Giessler K, Golub G, Afulani P. Providers and women's perspectives on person-centered maternity care: a mixed methods study in Kenya. Int J Equity Health. 2019; 18: 83. doi: 10.1186/s12939-019-0980-8

13. Mocumbi S, Högberg U, Lampa E, Sacoor C, Valá A, Bergström A, etal. Mothers' satisfaction with care during facility-based childbirth: a cross-sectional survey in southern Mozambique. BMC Pregnancy and Childbirth. 2019(19): 303 (2019)

14. Nilsson L, Thorsell T, Wahn EH, Ekstrom A. Factors influencing positive birth experience of first-time mothers. Nursing Research and Practice. 2013, doi: http://dx.doi.org/10.1155/2013/349124

15. Ahmed HM. Role of verbal and non-verbal communication of health care providers in general satisfaction with birth care: a cross-sectional study in government health settings of Erbil City. Reproductive Health. 2020, 17:35, https://doi.org/10.1186/s12978-020-0894-3

16. Mudiyanse RM, Weerasinghe GSM, Piyasinghe MK, Jayasundara JMH. Patint's Expectatins during Doctor patient communication and doctor's perception about patient's expectations in a Tertiary Care Unit in Sri Lanka. ARCHIVES OF MEDICINE. 2015; 6(12). 
17. Berhane A, Enquselassie F. Patient expectations and their satisfaction in the context of public hospitals. Patient Preference and Adherence. 2016;10: 1919-1928

dol: https://doi.org/10.2147/PPA.S109982

\section{Supplementary Files}

This is a list of supplementary files associated with this preprint. Click to download.

- questionniare.docx 